\title{
INVERTEBRADOS FÓSILES DEL PALEOZOICO DE SONORA, MÉXICO
}

\author{
Paleozoic invertebrates fossils from Sonora, México
}

\section{EPISTEMUS}

ISSN: 2007-8196 (electrónico)

ISSN: 2007-4530 (impresa)

Francisco Javier Cuen Romero ${ }^{1}$

José Eduardo Valdez Holguín ${ }^{2}$

Alejandra Montijo González ${ }^{3}$

Rogelio Monreal Saavedra 4

Recibido: 18 de septiembre de 2016 ,

Aceptado: 21 de noviembre de 2016

Autor de Correspondencia:

Dr. José Eduardo Valdez Holguín

Correo:jvaldez@guayacan.uson.mx

\section{Resumen}

A través de los fósiles es posible conocer la vida en el pasado geológico. La vida se originó en el mar hace $3700 \mathrm{Ma}$, siendo formas muy sencillas atribuibles a algas e invertebrados como las medusas; las primeras formas complejas se originaron a inicios del Paleozoico hace $541 \mathrm{Ma}$. El Paleozoico se divide en seis periodos: Cámbrico, Ordovícico, Silúrico, Devónico, Carbonífero y Pérmico; los cuales se caracterizan por una gran biodiversidad y abundancia de invertebrados. En Sonora se conocen diversas localidades con fósiles marinos del Paleozoico, destacando la presencia de poríferos, celenterados, braquiópodos, briozoarios, moluscos, artrópodos y equinodermos. El Paleozoico termina hace $252 \mathrm{Ma}$ con la mayor extinción conocida en la historia de la biosfera, culminando con el $95 \%$ de las especies marinas.

Palabras clave: Fósiles, Invertebrados, Paleozoico, Sonora.

\section{Abstract}

Through fossils it is posible to know about the life in the geological past. Life originated in the sea $3700 \mathrm{Ma}$, being easy forms attributable to algae and invertebrates as jellyfish. First complex forms originated in the Early Paleozoic 541 Ma. Paleozoic is divided into six periods: Cambrian, Ordovician, Silurian, Devonian, Carboniferous and Permian; which are characterized by high biodiversity and abundance of invertebrates. Various Paleozoic localities in Sonora with marine fossils are known, highlighting the presence of poriferans, coelenterates, brachiopods, bryozoans, molluscs, arthropods and echinoderms. The Paleozoic ends $252 \mathrm{Ma}$ with the largest extinction known in the history of the biosphere, culminating with $95 \%$ of marine species.

Keywords: Fossils, Invertebrates, Paleozoic, Sonora.

1 Universidad de Sonora / correo: francisco.cuen@ciencias.uson.mx

2 Universidad de Sonora / correo:jvaldez@guayacan.uson.mx

3 Universidad de Sonora. / correo:amontijo@geología.uson.mx

4 Universidad de Sonora. / correo: monreal@ciencias.uson.mx 


\section{INTRODUCCIÓN}

Se calcula que el planeta Tierra se formó hace 4600 millones de años (Ma), y los vestigios de vida más antiguos que se conocen datan de unos $3700 \mathrm{Ma}$ [1], los cuales han quedado plasmados en las diferentes rocas que cubren la superficie terrestre. A través del estudio de los fósiles, los geólogos y paleontólogos han sido capaces de trazar y describir el curso de la evolución de la vida en la Tierra; la Paleontología es la ciencia que se encarga del estudio de los fósiles y utiliza principios y métodos de la Geología y la Biología.

Los fósiles son los restos de organismos que vivieron en el pasado geológico, con una antigüedad mayor a 10000 años y constituyen evidencia directa de la distribución de la tierra firme y mares del pasado [2]; al morir un organismo se descomponen sus partes blandas, mientras que las partes duras (conchas, caparazones, huesos, madera, entre otros) se cubren con sedimentos, iniciándose un reemplazamiento de minerales como sílice y calcita.

Existen varios procesos de fosilización, como la conservación de insectos en ámbar y el reemplazamiento con minerales que actúan como agentes fosilizantes; también existen evidencias indirectas como son moldes, impresiones, huellas y galerías; por ejemplo las pisadas de dinosaurios, tubos de vermes e impresiones de hojas de plantas.

Los fósiles se encuentran en rocas sedimentarias, las cuales son el resultado de la erosión de rocas previamente existentes que se meteorizan y por acción del agua, aire o hielo son transportadas, finalmente por gravedad se depositan en capas horizontales llamadas estratos, cada capa se deposita arriba de los estratos más antiguos y se sepulta con estratos más jóvenes, a este principio se le conoce como ley de superposición. Los geólogos utilizan los fósiles para conocer la edad de las rocas por las relaciones que los estratos guardan entre si.

La evidencia fósil de los primeros animales data unos 650 Ma y es conocida como biota Ediacara [3]. Hace 541 Ma inició la Era Paleozoica con un evento sin precedente en la historia del planeta, conocido como Explosión de Vida Cámbrica, el cual hace referencia a la aparición repentina de la mayoría de los grupos de organismos que se conocen hoy en día [4]; A través de los seis periodos que conforman el Paleozoico (Cámbrico, Ordovícico, Silúrico, Devónico, Carbonífero y Pérmico) estos organismos fueron evolucionando, formando verdaderos ecosistemas que han quedado conservados como fósiles preservando características excepcionales. El final de la Era Paleozoica, hace $252 \mathrm{Ma}$, se presentó la extinción más grande conocida en la historia de la biosfera, desapareciendo el $95 \%$ de las especies marinas y el $70 \%$ de los vertebrados terrestres.

El objetivo del presente trabajo es mostrar la riqueza biótica de Sonora durante el Paleozoico. Lo anterior conlleva una exposición de los fósiles más representativos de los distintos periodos que lo conforman, los cuales se han recolectado en el estado.

\section{PALEOZOICO}

\section{Cámbrico}

Hace aproximadamente 541 Ma comenzó el Cámbrico, primer periodo de la Era Paleozoica, con una duración de 56 Ma representa la primera aparición de invertebrados marinos similares a los que se conocen hoy en día, entre los cuales dominaron los trilobites. Durante el Cámbrico la distribución de los mares y masas terrestres eran muy diferentes a la actual, Laurentia, un antiguo continente que hoy en día comprende los territorios de Estados Unidos de América, Alaska, Canadá y norte de México se encontraba ubicado sobre el ecuador, mientras que al sur existía un gran supercontinente denominado Gondwana, el cual comprende los actuales territorios de Sudamérica, África, India, Antártida y Australia; separados por un océano mundial Ilamado lapetus.

El término Cámbrico fue utilizado por primera vez por Adam Sedgwick en 1835 en el Reino Unido, lugar donde fueron estudiadas estas rocas por primera vez [5]. El Cámbrico se caracteriza por la primera aparición de organismos complejos con esqueletos mineralizados, originados durante la Explosión de Vida Cámbrica, lo cual les permitió que se conservaran como fósiles, al poseer partes duras que resisten los diferentes fenómenos geológicos para convertirse en roca. En un clima considerado cálido con tendencia al efecto invernadero, estos organismos prosperaron de manera exitosa, originándose en ese tiempo formas tan familiares como las esponjas, braquiópodos, caracoles, artrópodos y equinodermos.

Las esponjas, consideradas como organismos muy sencillos debido a que no constituyen tejidos verdaderos, fueron habitantes de los mares someros de este periodo, a diferencia de las esponjas actuales para las que se calculan unas 5150 especies y que habitan aguas un poco más profundas. En Sonora se conocen fósiles de esponjas de esta edad en Cerros La Proveedora, Cerros Las Mesteñas, Sierra de López, Sierra Agua Verde, San José de Gracia y Arivechi.

Los arqueociátidos, fueron un grupo de organismos marinos filtradores de naturaleza calcárea, parecidos a las esponjas, los cuales aparecieron durante el Cámbrico temprano, sin embargo, no se adaptaron a las condiciones cambiantes del clima y se extinguieron a mediados de este periodo. En Sonora se han recolectado estos organismos únicamente en el área de Caborca, destacando géneros como Ethmophyllum y Ajacicyathus.

Los braquiópodos, organismos compuestos 
por dos valvas desiguales y una estructura interna denominada lofóforo, que sirve para la alimentación, también aparecieron por primera vez durante este periodo,dominando los ambientes bentónicos de los mares del Cámbrico. En Sonora se conocen braquiópodos del Cámbrico en el área de Caborca y Sierra Los Ajos (Lingulella), San José de Gracia (Acrothele, Dictyonina y Linnarssonia), Sierra Agua Verde (Obolella) y Arivechi (Dictyonina) (Figura 1).

Los artrópodos estuvieron representados en su mayoría por los trilobites, los cuales se caracterizan por poseer el cuerpo protegido por un exoesqueleto de quitina, el cual estaba dividido longitudinalmente en tres zonas o lóbulos, característica de donde toman su nombre. Los trilobites descritos en Sonora son muy abundantes, conociéndose cerca de 90 especies, destacando los del área de Caborca donde se han documentado 35 especies, Sierra Huachuca y Sierra Mesteñas (Tricepicephalus), Sierra Los Ajos (Glossopleura), San José de Gracia (Peronopsis y Elrathina) y Arivechi (Ptychagnostus) (Figura 2).

Los equinodermos, estuvieron representados por formas extrañas, que no llegaron hasta nuestros días, algunos parecidos a crinoideos como es Gogia que se conoce del área de San José de Gracia. Se ha estimado que el $60 \%$ de los fósiles del Cámbrico corresponden a trilobites, el 30\% a braquiópodos y el 10\% restante está constituido por otros grupos como esponjas, moluscos, equinodermos o grupos problemáticos [6].

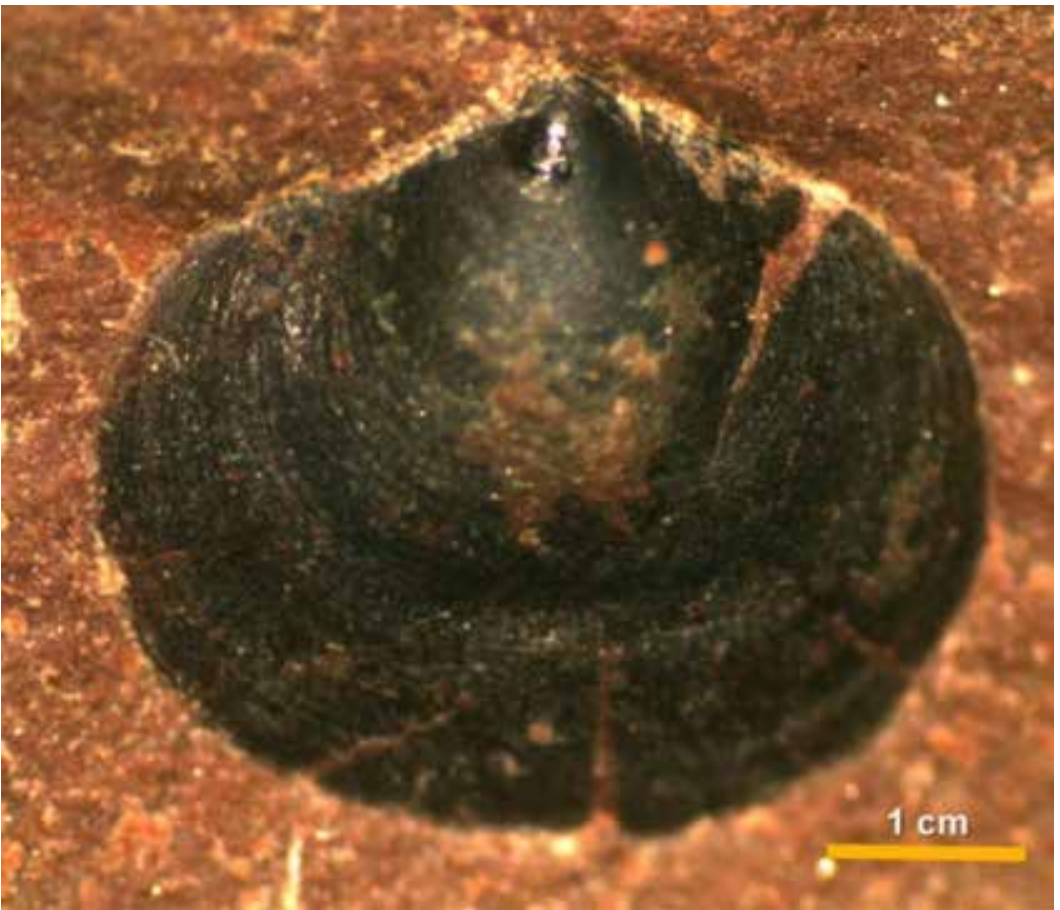

Figura 1. Braquiópodo del Cámbrico de San José de Gracia (Acrothele sp.)

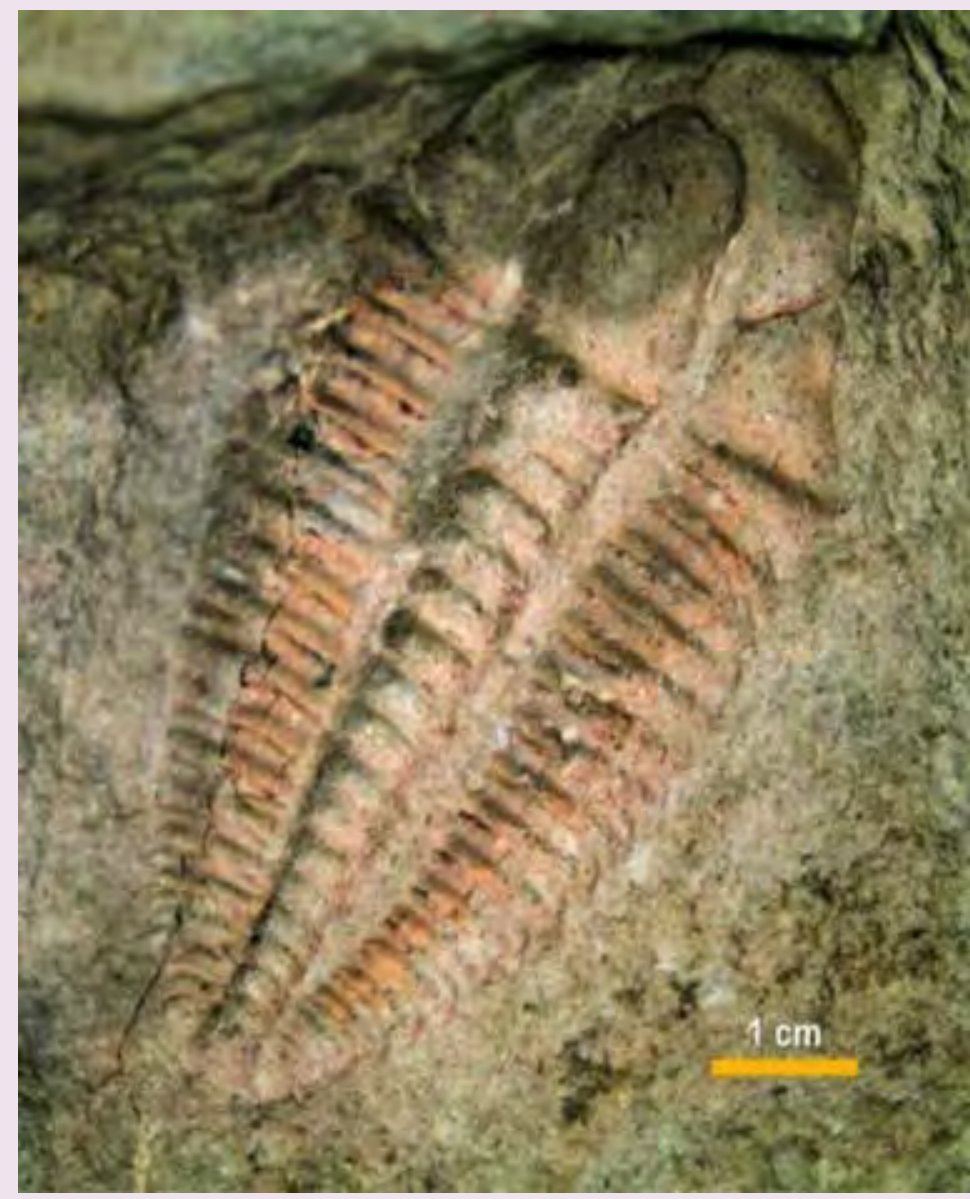

Figura 2. Trilobite del Cámbrico de San José de Gracia (Elrathina antiqua).

\section{Ordovícico}

El Ordovícico se inició hace unos $485 \mathrm{Ma}$, constituyendo el segundo periodo de la Era Paleozoica. Fue propuesto por Lapworth en 1879, en referencia a los Ordovicos, una tribu celta que habitó las Islas Británicas [7]. Se caracterizó por la desaparición y aparición de nuevas formas de invertebrados, los cuales se diversificaron rápidamente en el ambiente marino; estas formas nuevas corresponden principalmente a corales, briozoarios, equinodermos y graptolites, mientras que los trilobites, moluscos, esponjas, entre otras formas aparecidas durante el Cámbrico seguían prosperando en los mares someros.

Los mares someros del Ordovícico cubrieron grandes extensiones, en cuyas aguas seguían desarrollándose los equinodermos, sin embargo, durante el Ordovícico surgieron formas nuevas como los Echinoidea (erizos de mar), Holothuroidea (pepinos de mar), Asteroidea (estrellas de mar) y los Crinoidea (lirios de mar); estas formas se han mantenido hasta nuestros días y son parte de los ecosistemas marinos modernos (Figura 3). En Sonora se 
conocen fósiles de equinodermos de esta edad en Sierra de Mazatán y Rancho las Norias siendo crinoides.

Al inicio del periodo el clima se caracterizó por ser cálido con tendencia al efecto invernadero, sin embargo, a mediados de este comenzó un enfriamiento global culminando o finalizando como una glaciación, la cual provocó una extinción en masa que mermó fuertemente a las comunidades de trilobites, hasta entonces muy bien adaptadas. Respecto a la geografía, existían dos grandes océanos: el primitivo lapetus al oeste y hacia el este comenzaba la apertura del Paleo-Tethys; los continentes seguían principalmente en latitudes ecuatoriales [7]. En Sonora se conocen trilobites del Ordovícico en Rancho Pozo Nuevo (Kainella), Rancho Placeritos (Cryptolithoides) y Rancho Las Norias (Ectenonotus).

Un grupo importante que apareció durante el Ordovícico y que se extinguió a inicios del Carbonífero es el de los graptolites, cuyo nombre significa "escritura en piedra". Los graptolites fueron organismos coloniales, los cuales habitaron los mares del Paleozoico y posiblemente eran filtradores. En Sonora se han reportado graptolites del Ordovícico en Cerro Cobachi (Climacograptus), Tecoripa (Amplexograptus), Mina La Barita cerca de Mazatán (Dicranograptus) y en La Casita - Los Chinos (Orthograptus) (Figura 4).
Los briozoarios son organismos coloniales que aparecieron por primera vez durante el Ordovícico y aún habitan los mares actuales. En Sonora se conocen fósiles de briozoarios principalmente en Sierra Agua Verde.

Los corales, especialmente los tabulados formaron plataformas carbonatadas durante el Paleozoico, aparecieron en el Ordovícico y se extinguen en el Pérmico. En Sonora se conocen corales tabulados en La Casita Los Chinos (Paleophyllum), así como corales solitarios en Rancho Placeritos (Deiracorallium) y en Sierra Agua Verde (Streptelasma).

Por otra parte, durante el Ordovícico, los braquiópodos fueron formas comunes en los mares someros, conociéndose en Sonora en Rancho Pozo Nuevo (Orthidiella), Rancho Placeritos (Eoplectodonta), Rancho Las Norias (Hesperonomia), Sierra Agua Verde (Liricamera) y Arivechi (Lingulella). Los moluscos, entre ellos los bivalvos, gasterópodos y cefalópodos, también constituyeron un importante elemento biológico de los mares, los cuales fosilizaron y hoy en día se conocen en Rancho Pozo Nuevo (Lecanospira), Rancho Placeritos (Palliseria) y Rancho Las Norias (Maclurites). Desde el Ordovícico hasta la actualidad, los mares han sido dominados por grupos tan familiares como los corales, briozoarios, caracoles, bivalvos, cefalópodos y estrellas de mar.

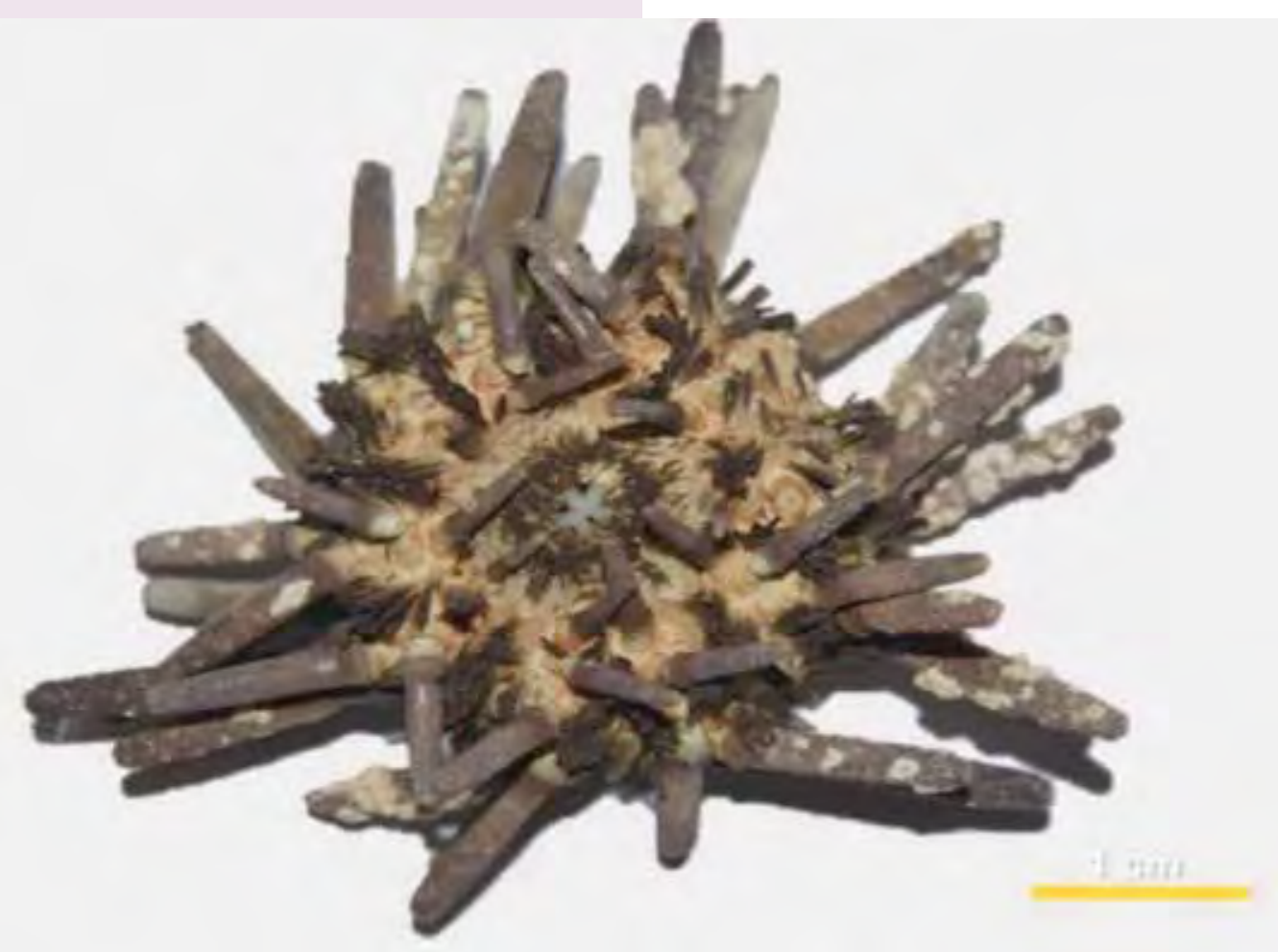

Figura 3. Erizo de mar (Eucidaris thouarsii) reciente del Golfo de California mostrando la linterna de aristoteles. Estos organismos se originaron durante el Ordovícico (Echinoidea) y han llegado hasta nuestros días. 
[1]. En Sonora, el Silúrico está pobremente representado, conociéndose solamente una localidad con fósiles de esta edad, Rancho Placeritos, donde se ha documentado la presencia de braquiópodos, gasterópodos, y crinoideos, destacando la presencia de corales tabulados como Halysites (Figura5).

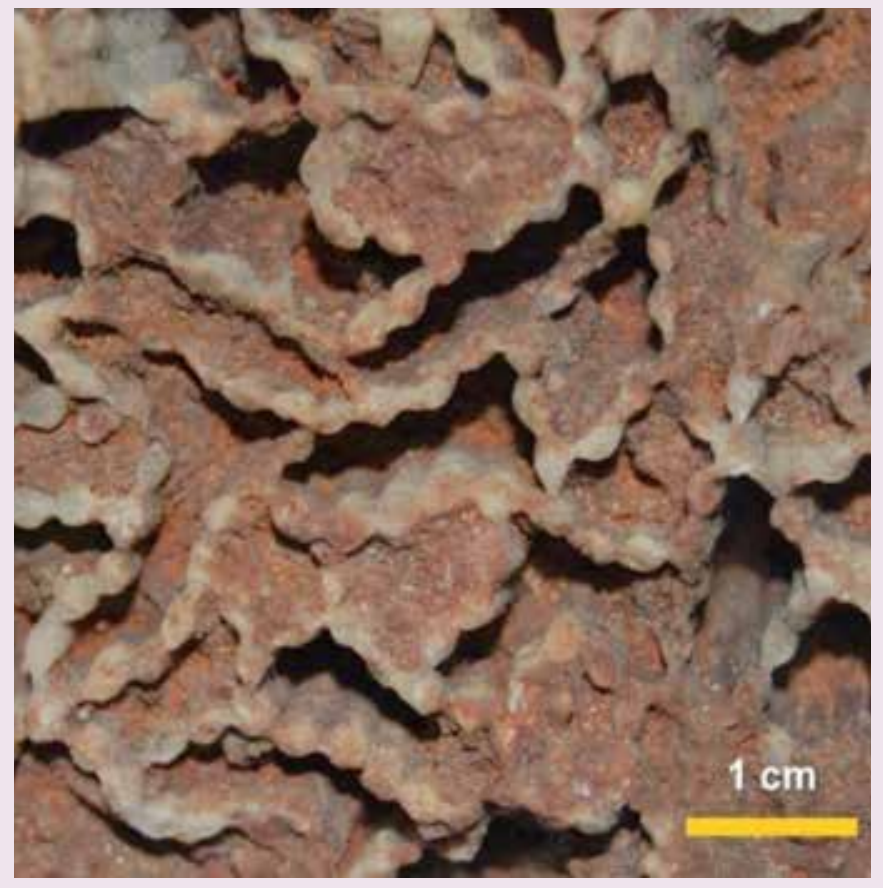

\section{Figura 4. Detalle de un graptolite (Dicranograptus sp.) Mina La Barita (Mazatán).}

\section{Silúrico}

El Silúrico se inicia hace unos $443 \mathrm{Ma}$, y corresponde al tercer periodo de la Era Paleozoica. Fue nombrado por Murchinson en 1939, en honor de los Siluros, una tribu que habitó las islas Británicas [8]. Durante el Silúrico se dio una rápida recuperación de la biodiversidad después el evento de extinción másiva de finales del Ordovícico; además de eventos sucesivos relacionados con el nivel del mar. Durante el Silúrico se dio la colonización de las plantas a tierra firme, abandonando el ambiente marino, y una paleogeografía marcada por el cierre del primitivo Océano de lapetus [8].

Durante el Silúrico se formaron montañas, desiertos y mares interiores que condujeron a extinciones en escala moderada [8]. Los arrecifes coralinos prosperaron en los mares, y abundaban braquiópodos, moluscos, trilobites y crinoides. Estos últimos contribuyeron a la formación de rocas encrinitas, formadas por la acumulación de cientos de placas articulares de estos equinodermos. También aparecieron algunos de los artrópodos más grandes conocidos en las historia de la Tierra, los Eurypterida, siendo escorpiones marinos con una longitud de hasta tres metros que habitaron los mares hasta finales del Pérmico

Figura 5. Detalle de Halysites sp. coral colonial del Silúrico. Rancho Placeritos.

\section{Devónico}

El Devónico es el cuarto periodo de la Era Paleozoica y se inicia hace unos 419 Ma. Fue nombrado por Sedgwick y Murchinson en 1839, en referencia a Devonshire, Reino Unido [9]. El Devónico se caracterizó por una alza generalizada del nivel del mar, invadiendo amplias zonas continentales, y la existencia de dos supercontinentes: Gondwana ubicado en el polo sur y Laurentia se situaba sobre el Ecuador y parte del hemisferio norte [9].

Durante el Devónico ocurrió la primera gran radiación de plantas terrestres y los mares estuvieron poblados por braquiópodos, moluscos, artrópodos, equinodermos, entre otros. También apareció un nuevo grupo de moluscos cefalópodos, los ammonites, los cuales se diversificaron rápidamente y poblaron los mares de la Tierra hasta finales del Cretácico en la Era Mesozoica. A finales del Devónico se diversificaron los artrópodos, apareciendo formas como los ciempiés, milpiés, arañas e insectos [9].

A finales del Devónico una extinción masiva afecto a más del $70 \%$ de los organismos. La causa fue un enfriamento global, ocurrido por el descenso de $\mathrm{CO}_{2}$ debido a los primeros bosques y vegetación [9]. 
En Sonora se conocen ocho localidades con fósiles del Devónico: Bisaní, Sierra El Tule, Cerro Las Mesteñas, Cerro Cabullona, Rancho Placeritos, Sierra Agua Verde, Mina La Barita y Cerro Cobachi. En estas localidades se han recolectado fósiles de corales solitarios y coloniales (Figura 6), braquiópodos (Figura 7), gasterópodos, equinodermos, entre otros.

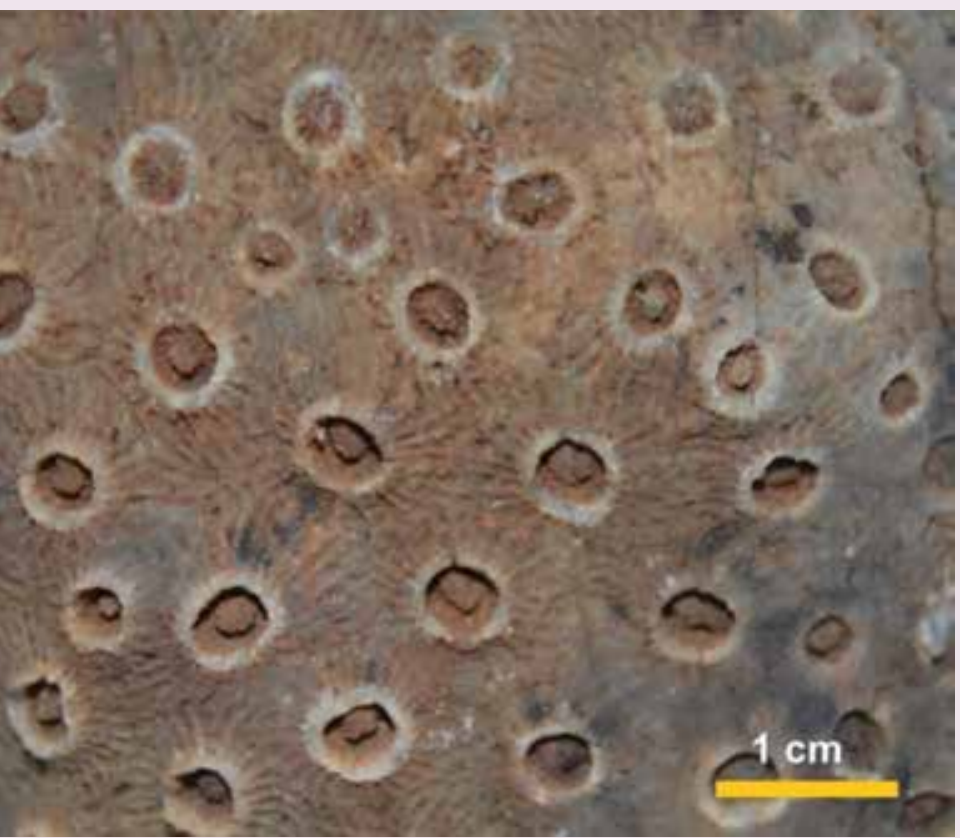

Figura 6. Detalle de un coral colonial no identificado del Devónico de Cerro Las Mesteñas.

\section{Carbonífero}

El Periodo Carbonífero fue nombrado en Europa por Conybeare y Phillips en 1822, debido a que los estratos de este periodo contienen depósitos de carbón [10]. En Estados Unidos de América, el Periodo Carbonifero ha sido dividido en Misisípico, en alusión a las rocas expuestas en el Río Misisipi y Pensilvánico, aludiendo a las rocas carbonosas de Pensilvania.

\section{Misisípico}

El Misisípico se inició hace 358 Ma y está marcado por grandes cambios a nivel global. El supercontinente Pangea cambió la circulación oceánica mundial, existiendo diferenciación biogeográfica. Las plantas terrestres se diversificaron provocando cambios atmosféricos notables.

Las formas de vida son muy similares a las del Devónico, como las esponjas, briozoarios, corales, moluscos, artrópodos y equinodermos. Los trilobites que habían sido muy exitosos durante el Paleozoico temprano comenzaron su declinación.

En Sonora se conocen 14 localidades con fósiles del Pensilvánico: Rancho Bisaní, Sierra El Tule, Sierra de los Ajos, Cerro Las Mesteñas, Cerro Cabullona, Sierra El Tigre, Rancho Placeritos, Sierra Santa Teresa, Rancho Las Norias, Cerro Las Trincheras, Sierra de Mazatán, Sierra Agua Verde, Cerro Cobachi y Arivechi. En estas localidades se ha reportado la presencia de corales coloniales (Syringopora, Michelinia, y Lithostrotion), corales solitarios (Caninophyllum, Cyathaxonia y Sychnoelasma), briozoarios ramosos, braquiópodos (Dielasma, Brachytyrina y Cyrtospirifer) moluscos (Avonia y Echinoconchus) y crinoideos (Figura 8).

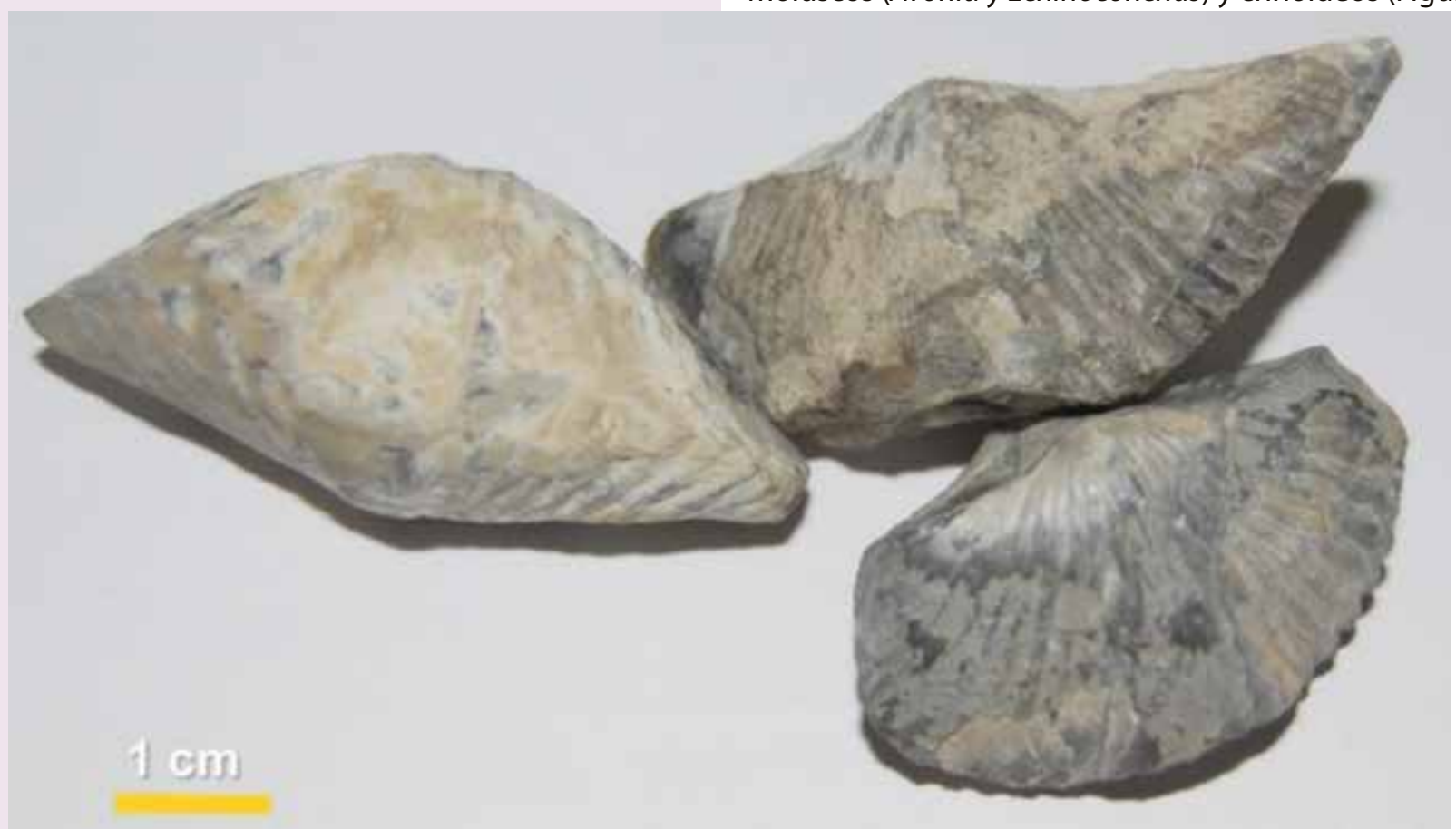

Figura 7. Braquiópodos (Punctospirifer sp.) del Devónico de Cerro Las Mesteñas. 


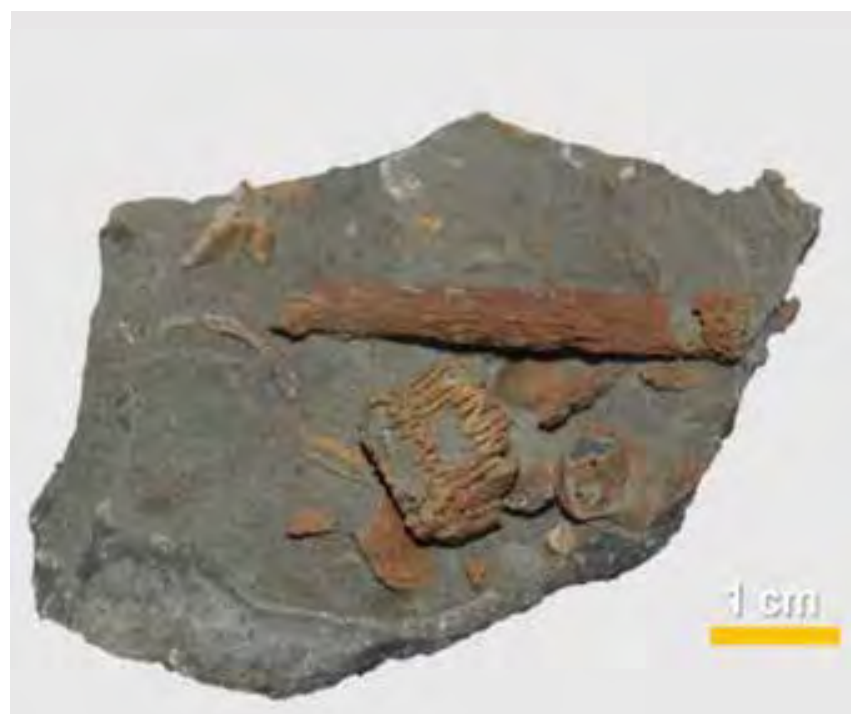

Figura 8. Placas articulares de crinoideos y radiolas de erizos de mar del Misisípico de Sierra Agua Verde.

\section{Pensilvánico}

El Pensilvánico inició hace $323 \mathrm{Ma}$, durante este subperiodo se formaron mares poco profundos con aguas cálidas, las cuales fueron pobladas por una gran diversidad de organismos como esponjas, corales, briozoarios, braquiópodos, moluscosy crinoideos. También aparecieron formas nuevas como los fusulínidos. Los insectos, entre ellos libélulas gigantes (Meganeura) de 75 centímetros de envergadura, se desarrollaron gracias a la exuberancia de las plantas y alto contenido de oxigeno de la atmosfera [10].

En Sonora se conocen nueve localidades con fósiles del Pensilvánico, Sierra El Tule, Cerros Las Mesteñas, Cerro La Morita, Sierra Hachita Hueca, Sierra Agua Verde, Sierra Santa Teresa, Mina La Barita y Sierra La Campaneria. Estas localidades poseen una abundante biota fósil constituida por fusulínidos (Fusulinella, Triticites y Fusulina), corales coloniales y solitarios, briozoarios (Fenestella), braquiópodos (Spirifer) y abundantes placas articulares de crinoideos, los cuales parecieran las faunas dominantes durante este periodo.

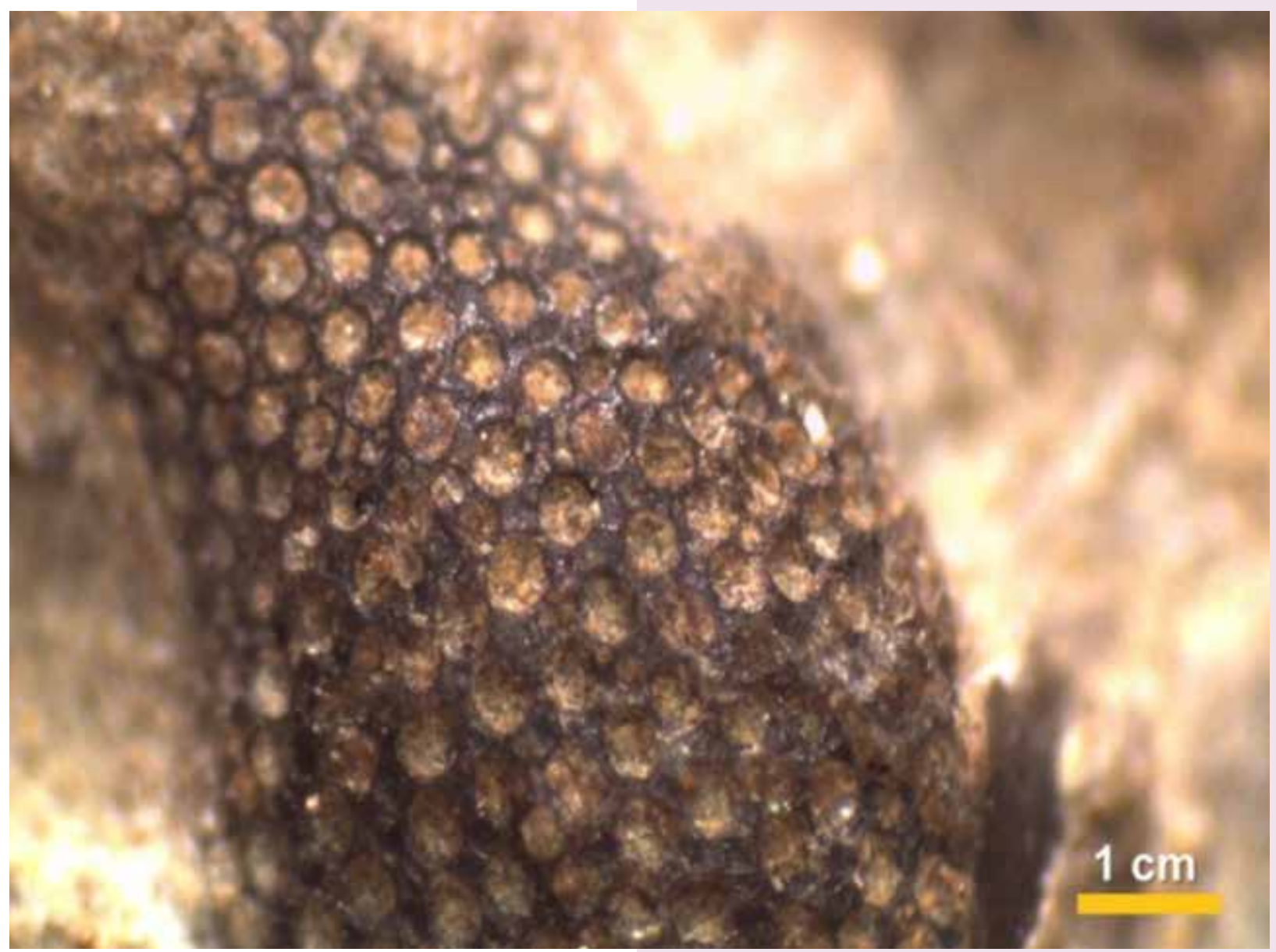

Figura 9. Briozoario ramoso del Pensilvánico de Sierra Agua Verde. 


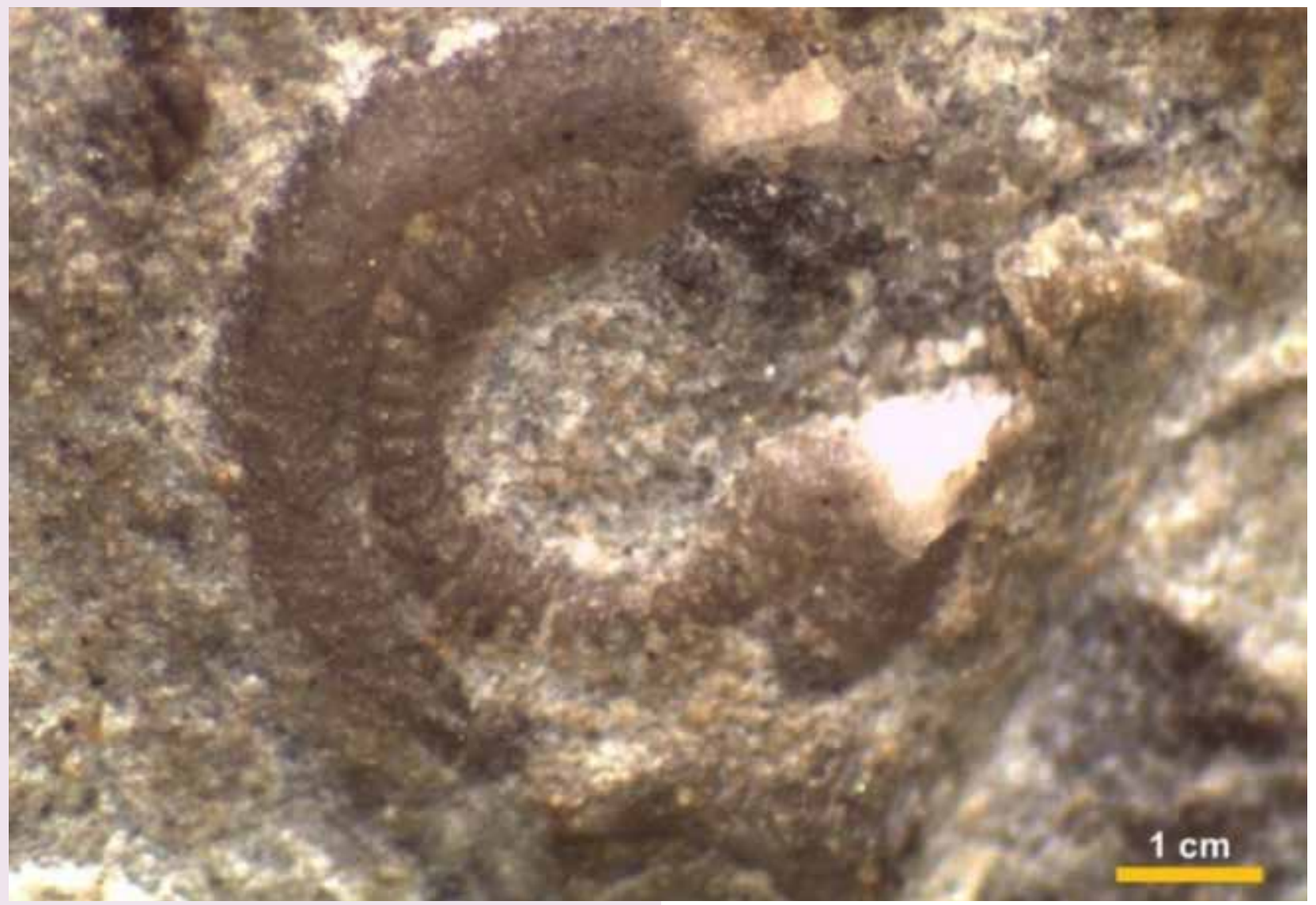

Figura 10. Crinoideos del Pensilvánico de Sierra Agua Verde.

\section{Pérmico}

El último periodo del Paleozoico lo constituye el Pérmico, que comenzó hace unos 298 Ma y terminó hace 252 Ma. Fue propuesto por Murchinson (1872) en Perm, Rusia [11]. Durante el transcurso del Pérmico se dio la mayor extinción ocurrida en la historia de la Tierra, debido principalmente al calentamiento global y avance de los desiertos. Está extinción es inclusive de mayores proporciones que la que acabó con los dinosaurios hace $66 \mathrm{Ma}$ [2]. En los mares pérmicos desaparecieron aquellos organismos que vivían fijos o próximos al sustrato, como lo fueron cierto grupo de corales, braquiópodos, briozoarios, amonoideos, crinoideos y completamente los trilobites y fusulínidos.

Muchos otros grupos animales encontraron un ambiente natural propicio, debido a la falta de competencia y continuaron su existencia en regiones tanto acuáticas como terrestres. En Sonora se conocen 13 localidades con rocas del Pérmico, como son Cerro Los Monos, Sierra El Tule, Cerro La Morita, Pilares de Teras, Sierra El Tigre, Sierra Hachita Hueca, Cerro Copete, Sierra Santa Teresa, Sierra Agua Verde, Cerro Cobachi, Sierra EI Aliso, Sierra La Campaneria y Cerro Santo Domingo. La biota es abundante y está compuesta por fusulínidos
(Parafusulina, Triticites y Skinnerella) espículas de esponja, corales (Lophophyllidium), braquiópodos (Dielasma, Liosotella y Stenocisma), ammonites (Waagenoceras) y placas articulares de crinoideos (Figura 11).

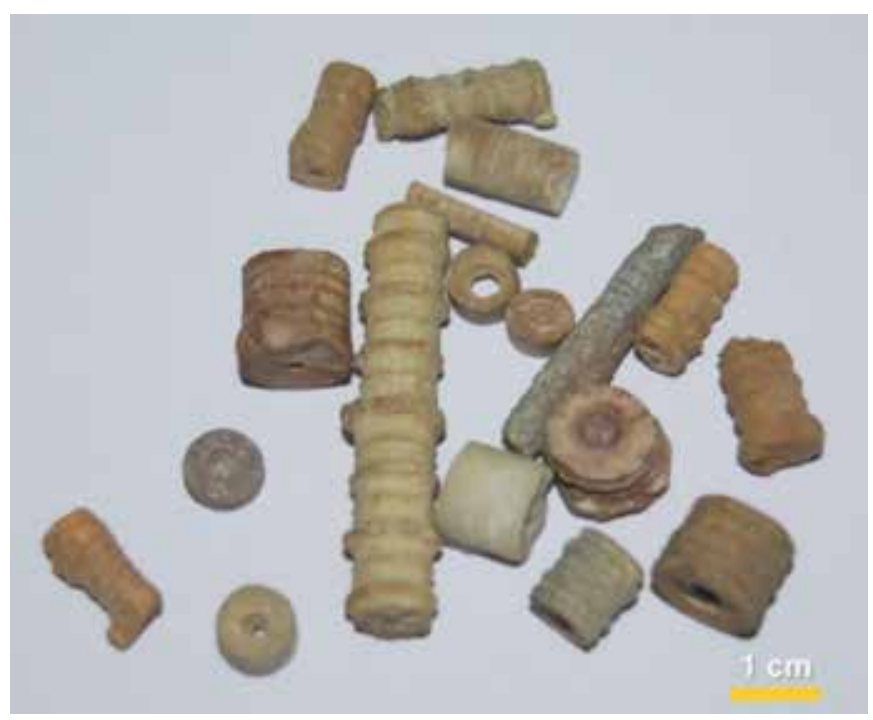

Figura 11. Placas articulares de crinoideos del Pérmico, Sierra El Tigre. 


\section{CONCLUSIÓN}

El estado de Sonora posee una abundante biota fósil, particularmente del Paleozoico, estando representados todos los periodos que lo componen. La biota fósil esta representada por esponjas, corales, braquiópodos, moluscos, artrópodos, equinodermos, entre otros. Los fósiles son importantes debido a que proporcionan información muy valiosa del pasado geológico, como es la edad relativa de las rocas que los contienen, la distribución de masas terrestres y mares, proporcionan información climatológica, son la prueba indiscutible de la evolución orgánica, constituyen importantes depósitos de hidrocarburos y ayudan a resolver complejos problemas geológicos. Por lo anterior, es irrefutable la importancia que estos tienen como patrimonio que debe ser preservado para la posterioridad.

\section{AGRADECIMIENTOS}

Francisco Cuen agradece al Posgrado en Biociencias del Departamento de Investigaciones Científicas y Tecnológicas de la Universidad de Sonora (DICTUS) por proveer las facilidades para llevar a cabo este trabajo, así como a CONACYT por el apoyo financiero. Este trabajo se encuentra enmarcado en los proyectos CONACYT No. 165826, 235970 y ECOS Francia-México No. 229494.

\section{BIBLIOGRAFÍA}

[1] A. C. Allwood, «Evidence of life in Earth's oldest rockso,» Nature, pp. 1-2, 2016.

[2] B. E. Buitrón Sánchez, E. Almazán Vázquez y M. C. Gómez Espinosa, Paleontología General Invertebrados, México: Universidad Nacional Autónoma de México, Facultad de Ingeniería, 2010, p. 317.
[3] A. Seilacher, D. Grazhdankin y A. Legouta, «Ediacaran biota: The dawn of animal life in the shadow of giant protist," Paleontological Research, vol. 7, n 1, pp. 43-54, 2003.

[4] A. Penumaka, «The Cambrian Explosion and the Origins of Diversity,» Harvard Science Review, pp. 44-47, 2011.

[5] S. Peng, L. Babcock y R. Cooper, «The Cambrian Period,» de The Geologic Time Scale 2012, vol. 2, F. M. Gradstein, J. G. Ogg, M. D. Schmitz y G. M. Ogg, Edits., China, Elsevier, 2012, pp. 437-488.

[6] F. J. Cuen Romero y L. Radelli Rocco, «Un problema estratigráfico en el Cámbrico y Precámbrico de Caborca, Sonora,» XXXI Semana Cultural de Geología, pp. 6-7, 2007.

[7] R. Cooper y P. Sadler, "The Ordovician Period," de The Geologic Time Scale 2012, vol. 2, F. M. Gradstein, J. G. Ogg, M. D. Schmitz y G. M. Ogg, Edits.,ii China, Elsevier, 2012, pp. 489-523.

[8] M. Melchin, P. Sadler y B. Cramer, «The Silurian Period,» de The Geologic Time Scale 2012, vol. 2, J. G. O. M. D. S. y. G. M. O. F. M. Gradstein, Ed., China, Elsevier, 2012, pp. 525-558.

[9] R. Becker, F. Gradstein y O. Hammer, «The Devonian Period,» de The Geologic Time Scale 2012, vol. 2, J. G. O. M. D. S. y. G. M. O. F. M. Gradstein, Ed., China, Elsevier, 2012, pp. 559-601.

[10] V. Davydov y M. Schmitz, «The Carboniferous Period,» de The Geologic Time Scale 2012, vol. 2, J. G. O. M. D. S. y. G. M. O. F. M. Gradstein, Ed., China, Elsevier, 2012, pp. 603-651.

[11] C. Henderson, V. Davydov y B. Wardlaw, "The Permian Period, $»$ de The Geologic Time Scale 2012, J. G. O. M. D. S. y. G. M. O. F. M. Gradstein, Ed., China, Elsevier, 2012, pp. 653-679. 